\title{
MORPHOTYPOLOGICAL ANALYSIS OF STARCH GRANULES THROUGH DISCRIMINANT METHOD AND ITS APPLICATION IN PLANT ARCHEOLOGICAL SAMPLES
}

\author{
WAN, Z. W. ${ }^{1}-$ LIN, S. P. ${ }^{1}-$ JU, M. ${ }^{1}-$ LING, C. H. ${ }^{2}-$ JIA, Y. L. ${ }^{1,3}-$ JIANG, M. X. ${ }^{1}-$ LIAO, F. Q. ${ }^{1 *}$ \\ ${ }^{1}$ Key Laboratory of Poyang Lake Wetland and Watershed Research Ministry of Education, \\ School of Geography and Environment, Jiangxi Normal University, Nanchang 330022, China
}

${ }^{2}$ State Key Laboratory of Lake Science and Environment, Nanjing Institute of Geography and Limnology, Chinese Academy of Sciences, Nanjing 210008, China

${ }^{3}$ Shandong Provincial Key Laboratory of Water and Soil Conservation and Environmental Protection, Linyi University, Linyi 276000, China

Corresponding author

e-mail: liaofuqiang@jxnu.edu.cn

(Received $8^{\text {th }}$ Jan 2020; accepted $6^{\text {th }}$ May 2020)

\begin{abstract}
Starch granule analysis effectively recovers microbotanical residues of starchy plants from archaeological contexts. Morphometric analysis is a common method to identify starch granules. However, this technique is time-consuming and inaccurate. Morphotypological differences in plants may also cause inconsistent results during microscopic observations. To address this problem, we evaluated the morphotypological features of three types of starch granules, specifically those found in wheat, millet, and yam, through light microscopy. Moreover, we used morphotypological analysis and discriminant analysis by ImageJ and SPSS software to perform computer-assisted analysis on the data set of geometric characteristics of the three types of starch granules, as well as the starch granule fossils from the Xianrendong and Diaotonghuan archaeological sites. Results are detailed and comparable to the light microscopy findings. The improved method with ImageJ and SPSS software required less time by direct measurement with a light microscopy and enhanced the accuracy of starch granule identification with the reduction of subjectivity. Therefore, the combination of ImageJ and SPSS software is a promising technique for the morphotypological analysis and identification of starch granules in archaeological starch granule analysis.
\end{abstract}

Keywords: archaeobotany, ancient recipes, neolithic revolution, geometric characteristic, microfossils, residue analysis

\section{Introduction}

The origin of agriculture and crop domestication in the Neolithic worldwide is becoming increasingly important in many disciplines (Diamond, 2002; Balter, 2007; Gremillion et al., 2014; Herzog et al., 2018; Mickleburgh et al., 2019; Li et al., 2020). Rice, millet, wheat, barley, and other types of mainstay crops have played very important roles in the early periods of human society around 12,000 years ago (Weber and Fuller, 2008; Lu et al., 2009; Jones et al., 2011). All these important crops comprise of up to 90\% starch (Torrence and Barton, 2006; Ciofalo et al., 2019; Zhu et al., 2020). However, considering that conservation conditions are poor in the archaeological context, few crop relics are found during excavation, which are difficult to identify (Moore, 1998). Thus, information on crop utilization and domestication remains limited, thereby impeding the reconstruction of crop domestication and origin of agriculture. To solve this problem, a novel method called starch granule analysis was developed, which was performed by identifying ancient starch fossils retrieved from 
archaeological contexts and comparing them with a modern plant starch morphology database.

Starch is a common component of higher plants (BeMiller and Whistler, 2009; Xu et al., 2019; Zhu et al., 2020). This molecule is mainly found in parenchymal cells in the form of semi-crystalline granules with birefringence characteristics, which are manifested through Maltese crosses under polarized light microscopy. Starch granules from various plants exhibit different structures and diagnostic features, which are controlled by genetic and environmental diversity (Torrence and Barton, 2006; Mercader, 2009; Yang et al., 2012). The morphotypological differences of starch granules are essential for the identification of vegetal residues, particularly food and plant remains from archaeological contexts. Starch granules have been considered an important factor to interpret ancient plant information because such granules can survive on the surface of archaeological tools, dental calculus, cultural deposits, and other contexts for up to more than 50,000 years (Torrence and Barton, 2006; Barton and Torrence, 2015). Furthermore, starch granule analysis has provided novel insights into paleoethnobotany and agricultural archaeology (Piperno et al., 2009). Thus, identification of ancient starch granules has become a primary approach to investigate agriculture origins, plant utilization by ancient people (Wan et al., 2012a), and paleoenvironment reconstruction (Lentfer et al., 2002; Vojtekova et al., 2019).

For instance, some plant residues are occasionally found during excavation with serious damage, which cannot be identified by traditional methods. Consequently, Ugent et al. (1981) first employed this new method to retrieve starch granule fossils from eight archaeological sites in central and southern Peru and confirmed that the plant relics belong to sweet potato (Ipomoea batatas) dating from 1,000 AD to 1,500 AD. Ugent et al. (1987) also used this method to demonstrate that aboriginal peoples who lived in Chile utilized potato (Solanum tuberosum) as early as 13,000 BP before the beginning of the Neolithic agricultural revolution. If starch granule analysis was not used to identify ancient plant relics, plant species can only be confirmed using incomplete plant fragments.

As a result, reconstruction of ancient plant utilization requires accurate identification of ancient starch granules (Piperno et al., 2004; Torrence and Barton, 2006). However, traditional methods to identify such granules mainly rely on morphometric analysis by comparing the starch granules retrieved from archaeological contexts with modern starch granule reference data in terms of properties such as shape, size, hilum position, surface ornament, and other anatomical features (Coster and Field, 2015; Farley et al., 2018). All these variants are recorded by directly observing plant specimens through microscopy, and identification almost entirely depends on personal judgment, which is also a laborious procedure. Nevertheless, few studies on the comprehensive geometric characteristics of these starch granules have been conducted with computer-assisted methods (Wu and Wang, 2011). Consequently, the data recorded by various individuals or at different instances by the same person may result in diverse outcomes because of the lack of consistent recording standards. Thus, scientists often require much time to confirm the sources of starch granules and precisely identify such sources.

According to previous studies, some of the common types of Triticeae seeds, such as wheat and barley, are composed of starch granules with bimodal size feature, that is, this type of starch can be either large or small (Yang and Perry, 2013). Morphotypological changes in Triticeae maturation significantly influence the accuracy of identification. These changes also require further research and elucidation (Wu et al., 
2014). Therefore, we aimed to evaluate the morphotypological changes in different stages of wheat maturity through light microscopy. Our previous studies indicated that the usual starch type can be divided into three geometric categories, namely, polygonal (as in millet), round (as in wheat), or oval (as in yam) (Wan et al., 2011a). Accordingly, we evaluated the morphotypological features of modern millet and yam.

We used ImageJ software for computer-assisted analysis of the geometric characteristics of starch granules. The outcomes were then used to identify ancient starch granules retrieved from Xianrendong and Diaotonghuan sites in China dating from the late Paleolithic to the early Neolithic period (Wan et al., 2012b). The proposed method required less time and exhibited greater efficiency than previous methods. Our experimental results confirmed that starch granules from wheat are characterized by different types of granules at different stages and determined the geometric features of three modern crops common in China. Photomicrographs of starch granules from millet, wheat, and yam were obtained through light microscopy and analyzed using ImageJ and SPSS software. Comparison of the ancient starch granules with modern samples by using computer-assisted analysis reduced the subjectivity of starch granule identification. Furthermore, the proposed method enhanced the efficiency and accuracy of measurement.

\section{Materials and methods}

\section{Materials}

Wheat (Triticum aestivum) was planted in Xichuan County, Henan, China and then collected in the late stage of wheat maturity. Six batches of wheat seeds were collected on May 5, 8, 11, 15, 20, and 26, 2014 and correspondingly labeled as W1 to W6. W6 was composed of fully mature wheat seeds. There are 5 grains of wheat in each batch.

Millet (Setaria italica) and yam (Dioscorea opposita) consist of one type of starch granule each. Thus, in this study, only the mature samples were collected. Millet samples were obtained from Chaoyang County, Liaoning, China in the autumn of 2017, and yam samples were obtained from Nanchang County, Jiangxi, China in the winter of 2018. The millet sample used in the experiment was 5 grains, and the yam sample was $3 \mathrm{~g}$.

Ancient starch granule samples were retrieved from the Xianrendong and Diaotonghuan sites located in eastern Jiangxi, China dating to 20,000 12,000 cal. a BP. Two agricultural tools were examined in our previous study, and more than 200 starch granule fossils were retrieved from residues on the surface of these tools. Based on direct identification under microscopy, these ancient starch granules might have come mainly from species within Pooideae, Paniceae, and unidentified underground tubers.

\section{Methods}

\section{Modern observation of starch granules}

Plant starch granules were observed using modern sample methods as previously researches (Piperno et al., 2004; Perry et al., 2007). Briefly, a small amount of sample was placed in a $15 \mathrm{~mL}$ disposable plastic test tube. Afterward, $5 \mathrm{~mL}$ of ultrapure water was added, and the sample was soaked for more than $12 \mathrm{~h}$. The sample was then ground using a glass rod until it was completely broken. The solution was stirred using a rod. 
Subsequently, $200 \mu \mathrm{L}$ of the starch suspension was drawn and transferred to a glass slide. A drop of a solution containing 50\% glycerol and 50\% water was applied. The specimen was covered with a cover slip.

The slides were viewed under a Nikon ECLIPSE 50iPOL microscopy at $400 \times$ magnification. The photomicrographs of the starch granules were obtained using a digital camera. The size of each granule was recorded using a scale under the microscopy.

\section{Morphotypological analysis}

Image $\mathrm{J}$ is an image processing software developed by the National Institutes of Health (USA). This software can be used in biological studies to analyze geometric characteristics, such as length, angle, area, major axis, minor axis, perimeter, roundness, Feret's diameter, best-fitting ellipse, and centroid coordinates (Schneider et al., 2012). In this study, ImageJ 1.48 (download at http://rsbweb.nih.gov/ij/ index.html) was employed to analyze the images of starch granules. The Straight Line and Set Scale tools were used to ensure that the images were set at the desired scale. The image was then changed to 8-bit grayscale. The images were converted to binary images through binarization by using the Make Binary tool. Geometric characteristics were obtained by selecting Analyze Particles under the Analyze menu bar.

Since most starch granules are irregularly shaped, it is difficult to describe their size in terms of diameter. Therefore, the Feret's diameter is used for measurement. Feret's diameter is the size of an object measured in a certain direction (Isobe et al., 2013; Drazic et al., 2016). Generally speaking, the measurement method is defined as the distance between two parallel planes. These two parallel planes need to jam the object and be perpendicular to the specified direction.

\section{Comparison with ancient starch granules}

To test the effectiveness of identification criteria obtained from ImageJ software analysis, ancient starch granules retrieved from the Xianrendong and Diaotonghuan sites, Jiangxi, China were selected as test samples (Wan et al., 2012b). The images of ancient starch granules were preliminarily identified as Pooideae, Paniceae, and unidentified underground tubers and then measured using ImageJ. Consequently, a series of geometric characteristics was obtained and used as identification criteria for precise species-level identification. The overall experiment and method were conceived and completed in 2019.

\section{Results}

\section{Morphotypological analysis of wheat starch}

Six slides corresponding to W1 to W6 were observed through microscopy. A representative image from each sample is shown in Figure 1. Based on the measurement analysis results (Figure 2), the size of the wheat starch granule gradually increased from $3.23 \mu \mathrm{m}$ to $22.48 \mu \mathrm{m}$ during maturity. The starch granules can be divided into two groups, namely, large group $(>10 \mu \mathrm{m})$ and small group $(<10 \mu \mathrm{m})$. The percentage of starch granules belonging to the large group exhibited an increasing trend from W1 to W6 (Table 1). 

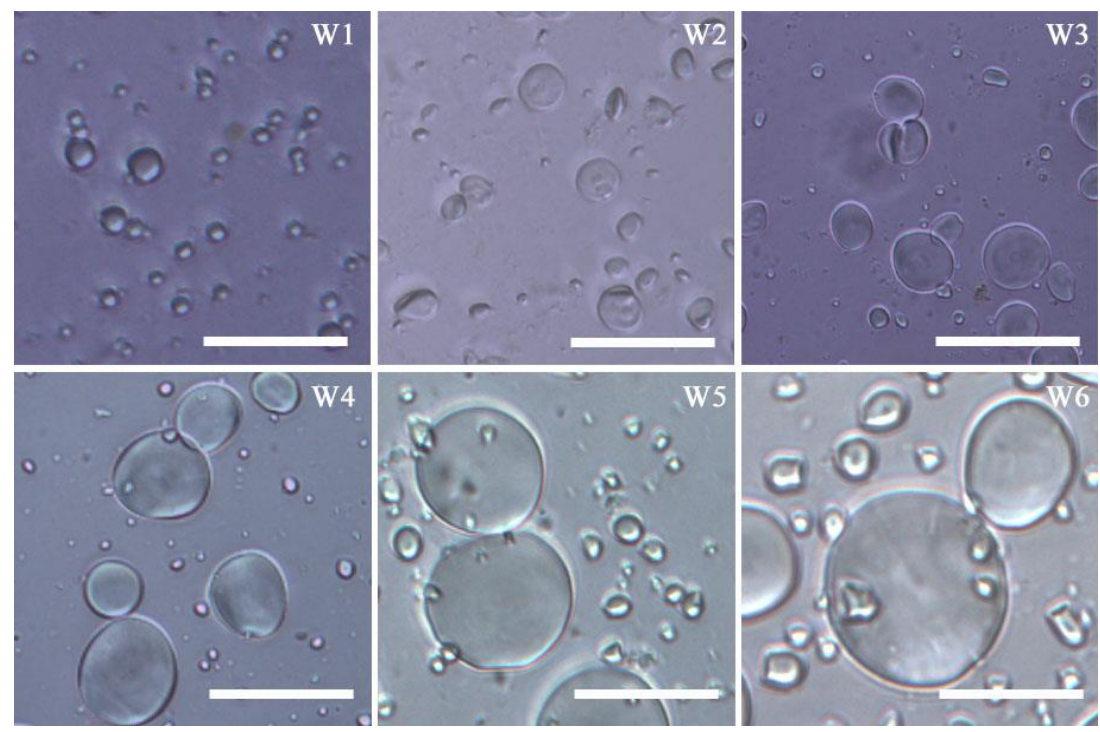

Figure 1. Wheat starch granules from different stages (W1 to W6). Scale bar $=20 \mu \mathrm{m}$

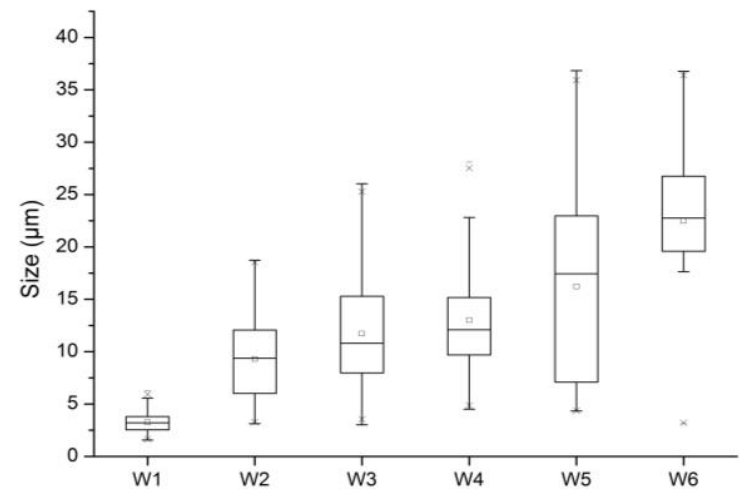

Figure 2. Box-whisker plot of the starch granule size from W1 to W6

Table 1. Percentages of large group $(>10 \mu \mathrm{m})$ and small group $(<10 \mu \mathrm{m})$ from W1 to W6

\begin{tabular}{c|c|c|c|c|c|c}
\hline Group & W1 & W2 & W3 & W4 & W5 & W6 \\
\hline Big group & 0 & 45 & 57 & 72 & 64 & 91 \\
Small group & 100 & 55 & 43 & 28 & 36 & 9 \\
\hline
\end{tabular}

\section{Morphotypological analysis of millet and yam starch}

Millet contains polygon starch granules showing centric and closed hila, as well as indemonstrable lamellae (Figure 3A). Some granules exhibited fissures across the hila under light microscopy. Millet starch granules showed wrinkled surfaces and coarse edges, which may have been caused by contact with the other starch granule. The mean size of millet starch granule was $9.47 \mu \mathrm{m}$, which was almost $70 \%$ smaller than $15 \mu \mathrm{m}$.

Yam is composed of singular starch granules that are oval and exhibiting eccentric hila (Figure 3B), and the mean size is $30.89 \mu \mathrm{m}$. Almost $80 \%$ of the granules measured within $26.13 \mu \mathrm{m}$ to $36.76 \mu \mathrm{m}$ in size. The lamellae of yam starch granule were evident under light microscopy. 

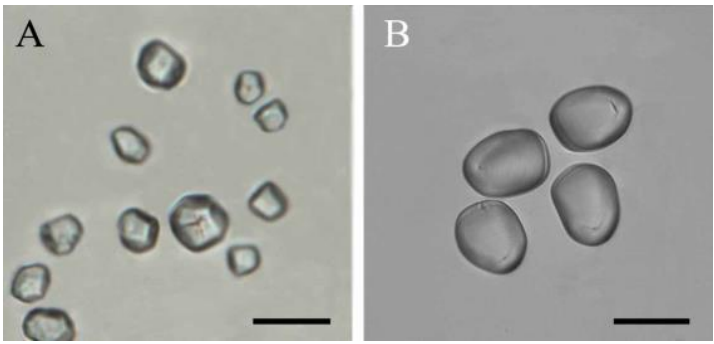

Figure 3. (A) Starch granule from millet (Setaria italica), Scale bar $=10 \mu \mathrm{m}$. (B) Starch granule from yam (Dioscorea opposita), Scale bar $=30 \mu \mathrm{m}$

\section{Morphotypological analysis in ImageJ}

For wheat, each image at different stages was processed using ImageJ software. W4 was considered as representative of the results obtained in each stage because this sample was obtained in the middle stage (Figure 4A). W4 picture was selected as a sample to show how to use ImageJ software for analysis. W4 image was changed to 8-bit grayscale such that only white and black pixels were present. As a result, this image was easily converted to a binary image. In the binary image, the starch granule appeared as a solid black region, and the other components appeared white (Figure 4B). These steps were accomplished through computer-assisted analysis, which was more efficient than the manual process. In the final step (Figure $4 C$ ), the software was used to extract the outline of each granule and determine the centroid area. In Figure $4 D$, the centroid area appears as a small point.
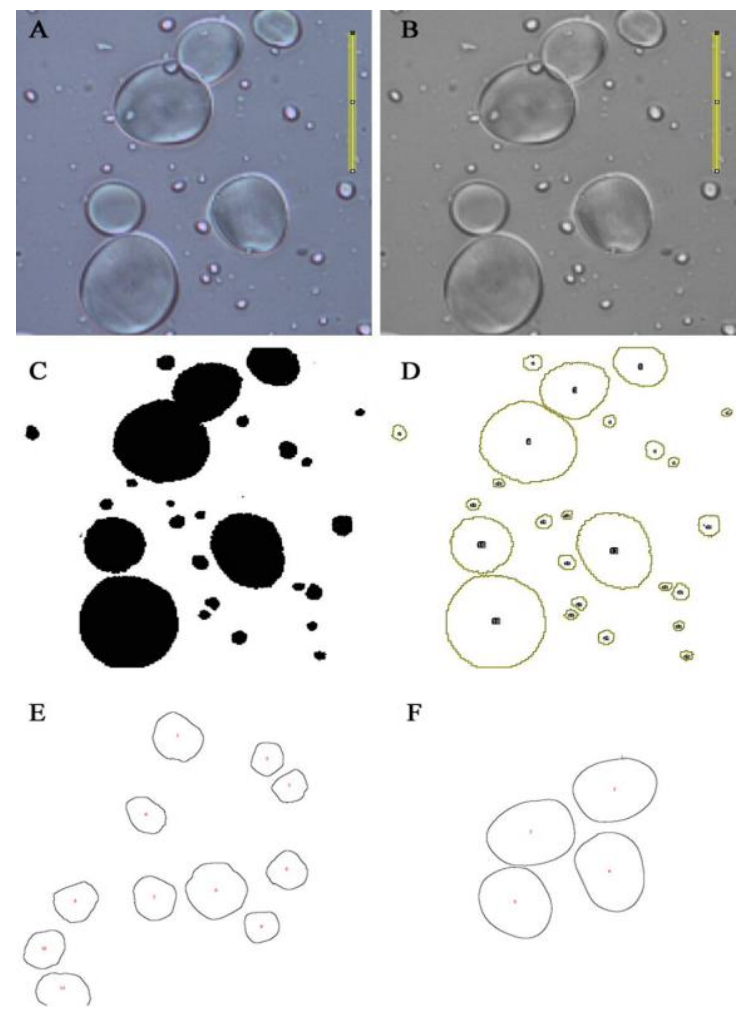

F

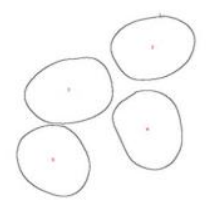

Figure 4. ImageJ analysis of microscopy image. (A) Setting the scale; (B) Converting the image to 8-bit grayscale; $(C)$ Converting to a binary image; (D) Extracting the outline of wheat starch granule; $(E)$ Outline of millet starch granule; $(F)$ Outline of yam starch granule 
Using the same procedure, the starch granule images of millet (Figure $3 A$ ) and yam (Figure $3 B$ ) can also be processed, and the results are shown in Figures $4 E$ and $4 F$.

\section{Geometric characteristics}

The geometric characteristics were simultaneously determined when the outline of each starch granule was obtained. The results of each variant are listed in Table 2. Given that the size of each wheat granule ranged from $3.23 \mu \mathrm{m}$ to $22.48 \mu \mathrm{m}$, particles smaller than $3.23 \mu \mathrm{m}$ were not considered starch granules and may have been impurities from the slide preparation. The geometric characteristics of millet and yam starch granules were also analyzed (Table 2).

Table 2. Geometric characteristics of starch granules

\begin{tabular}{c|c|c|c|c|c|c}
\hline No. & Area & Perimeter & Major axis & Minor axis & Feret's diameter & Roundness \\
\hline 1 & 58.90 & 30.4652 & 9.8877 & 7.5845 & 10.1213 & 0.767 \\
2 & 7.90 & 10.9113 & 3.3929 & 2.9646 & 3.662 & 0.874 \\
3 & 103.96 & 41.1647 & 12.3914 & 10.6821 & 12.9468 & 0.862 \\
4 & 211.28 & 57.9286 & 17.455 & 15.4117 & 17.6822 & 0.883 \\
5 & 9.32 & 11.9841 & 3.6261 & 3.2725 & 3.8949 & 0.902 \\
6 & 154.5 & 51.9203 & 15.628 & 12.5874 & 16.2413 & 0.805 \\
7 & 12.55 & 14.4326 & 4.147 & 3.8531 & 4.4944 & 0.929 \\
8 & 94.87 & 40.0049 & 11.082 & 10.8999 & 11.6726 & 0.984 \\
9 & 7.00 & 10.277 & 3.3057 & 2.6962 & 3.6125 & 0.816 \\
10 & 259.54 & 63.7831 & 18.4037 & 17.9559 & 19.0547 & 0.976 \\
11 & 26.962 & 19.856 & 6.307 & 5.443 & 6.579 & 0.863 \\
12 & 12.52 & 13.379 & 4.311 & 3.697 & 4.36 & 0.858 \\
13 & 12.245 & 13.514 & 4.273 & 3.648 & 4.486 & 0.854 \\
14 & 16.077 & 15.438 & 5.254 & 3.896 & 5.361 & 0.742 \\
15 & 17.106 & 15.879 & 4.763 & 4.573 & 5.02 & 0.96 \\
16 & 38.823 & 23.471 & 7.135 & 6.928 & 7.419 & 0.971 \\
17 & 21.978 & 17.829 & 5.681 & 4.926 & 5.792 & 0.867 \\
18 & 19.586 & 17.094 & 5.357 & 4.655 & 5.51 & 0.869 \\
19 & 13.064 & 13.607 & 4.178 & 3.981 & 4.446 & 0.953 \\
20 & 18.355 & 16.306 & 5.363 & 4.358 & 5.535 & 0.813 \\
21 & 22.491 & 18.59 & 6.558 & 4.367 & 6.534 & 0.666 \\
22 & 528.044 & 87.251 & 29.137 & 23.075 & 29.11 & 0.792 \\
23 & 580.795 & 91.363 & 30.92 & 23.916 & 30.562 & 0.774 \\
24 & 535.515 & 88.595 & 30.118 & 22.639 & 30.146 & 0.752 \\
25 & 507.801 & 85.375 & 27.734 & 23.312 & 27.958 & 0.841 \\
\hline
\end{tabular}

Note: Nos.1 10 represents wheat starch granules; Nos.11 21 represents millet starch granules; Nos.22 25 represents yam starch granules

\section{Archaeological application}

To demonstrate the effectiveness of morphotypological analysis and identification by ImageJ software, different starch granule fossil residues (Figures $5 A \sim C$ ) were retrieved from Xianrendong and Diaotonghuan sites, which are important early human 
archaeological sites in Jiangxi, China dating from 20,000 12,000 cal. a BP. These archaeological starch granule images were analyzed using ImageJ software, and a series of geometric characteristics was obtained and compared with the modern plant data, thereby facilitating rapid identification of the species of these starch fossils with enhanced accuracy. The final images processed using ImageJ software are shown in Figures $5 D \sim F$, and the geometric characteristics of each archaeological starch granule fossil were also obtained (Table 3).

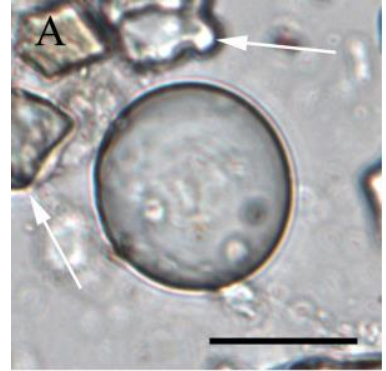

$\mathrm{D}$

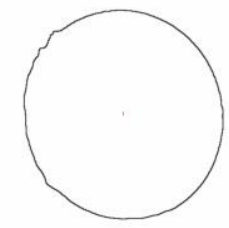

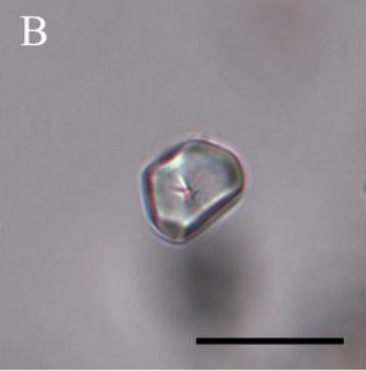

$\mathrm{E}$

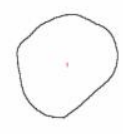

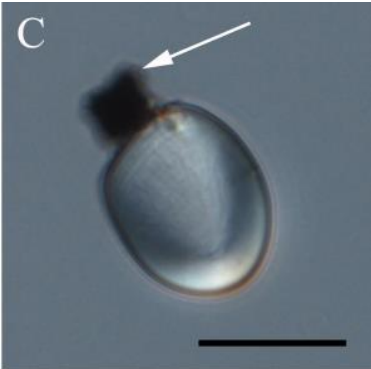

$\mathrm{F}$

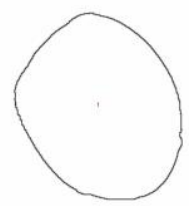

Figure 5. Archaeological starch granule retrieved from tools found in the Xianrendong and Diaotonghuan sites. The white arrowhead highlights impurities that are very common in archaeological sample. (A C) Images obtained under a light microscope; (D F) Images processed using ImageJ software. Scale bar $=20 \mu \mathrm{m}$

Table 3. Geometric characteristics of archaeological starch granules from Xianrendong and Diaotonghuan sites

\begin{tabular}{c|c|c|c|c|c|c}
\hline No. & Area & Perimeter & Major axis & Minor axis & Feret's diameter & Roundness \\
\hline 1(Fig.5A) & 598.448 & 92.519 & 28.528 & 26.709 & 29.013 & 0.936 \\
\hline 2(Fig.5B) & 161.891 & 48.568 & 15.668 & 13.156 & 15.763 & 0.84 \\
\hline 3(Fig.5C) & 378.761 & 74.071 & 24.228 & 19.905 & 24.703 & 0.822 \\
\hline
\end{tabular}

The geometric characteristics of the three types of starch granules in wheat, millet, yam, and the ancient starch granule fossils were calculated by ImageJ software, and sufficient variants became available for construction of a discriminant formula by SPSS 20 software. The analysis results are shown in Figure 6, indicating that all scatter points have been clustered into three groups corresponding to wheat, millet, and yam starch granules. The ancient starch granules can thus be automatically allocated to their corresponding groups. Ancient starch granules in Figure $5 \mathrm{~A}$ are classified as wheat, those in Figure $5 B$ are classified as millet, and those in Figure $5 C$ are classified as yam. 


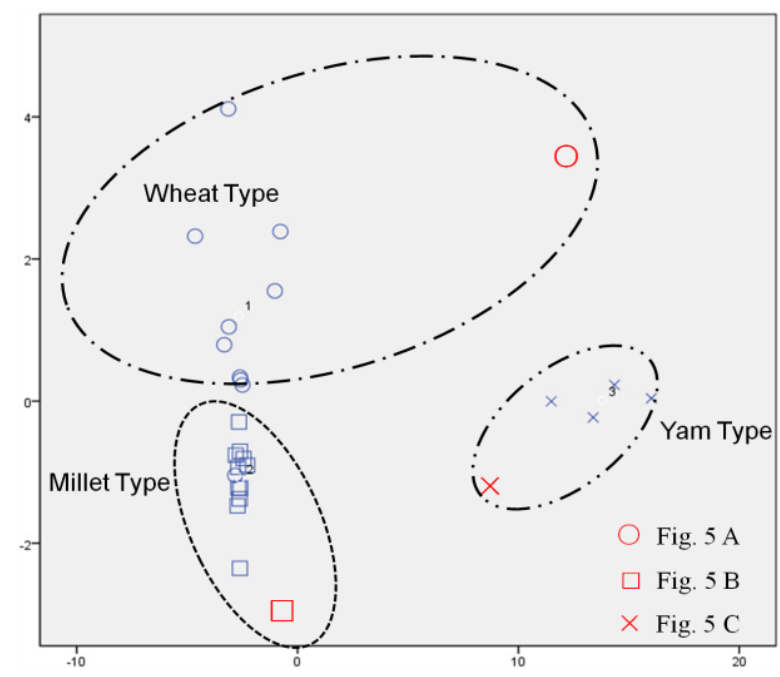

Figure 6. SPSS discriminant scatter plot of the three types of starch granules. The red dot indicates ancient starch granule fossils retrieved from Xianrendong and Diaotonghuan archaeological sites

\section{Discussion}

China is an important agricultural origin center and a domestication center for crops. Many crops such as millet, rice, barley, barley, etc. have played an important role in the agricultural development of Chinese history. Recently, Li et al. (2020) studied the changes of starch grains of four crops such as rice (Oryza sativa L.), foxtail millet (Setaria italica), Job's tears (Coix lacryma-jobi L.) and barley (Hordeum vulgare L.) after different milling methods, and explained that the treatment methods have different effects on starch grains. Zupancich et al. (2019) used 3D modeling and spatial analysis to reveal the function of grounding stones. And Owen et al. (2019) used ancient starch analysis on grinding stones to discuss plant utilization. All these indicate that there is an urgent need for a fast and stable starch granule identification method and process (Peng et al. 2019).

Although some physical means and chemical analysis reagents are used in the extraction of starch granules from archeological samples, such as ultrasound, hydrochloric acid, etc., related studies (Cuthrell and Murch, 2016; Yang, 2017) have shown that these means have a smaller effect on the shape of starch granules at lower intensity. Research and analysis of related foods and starch granules show that the changes in morphology and physicochemical properties of starch granules during processing are mainly caused by heating (Henry et al., 2009; Barton and Torrence, 2015). Considering that starch granule analysis experiments are carried out at normal temperature, the properties and morphology of starch granules are generally not affected by changes in identification.

Three other aspects of starch identification have to be addressed. First, the results of this study confirmed that wheat starch granule size gradually increases with wheat seed growth. The mean size of the six samples increased from $3.23 \mu \mathrm{m}$ to $22.48 \mu \mathrm{m}$; this value is similar to that obtained in our previous study in northern China (Wan et al., 2011b). We also confirmed that wheat starch can be divided into two groups of granules: the large group and the small group (Piperno et al., 2004). This grouping is an important identification criterion in research related to archaeobotany and ancient diet 
reconstruction (Piperno et al., 2004; Yang and Perry, 2013; Calo et al., 2019; Kendal et al., 2019).

The second problem is related to the data set of geometric characteristics of the three types of starch granules. Only the major axis of each granule was recorded in previous studies because appropriate tools to accurately describe the shape of starch granules were lacking (Wan et al., 2012a). This process is thus inaccurate and time-consuming. In the present study, ImageJ software was used to process the images obtained using a digital camera during light microscopy. The results showed that a series of geometric characteristics, including the area, perimeter, major axis, minor axis, Feret's diameter, and roundness, can be simultaneously obtained. The number of obtained variants corresponds to the accuracy of the identification. Hence, we can identify a starch granule from archaeological contexts based on the multivariate criteria without relying solely on the major axis data. Feret's diameter is different from the major axis (Table 2); in particular, the former is greater than the latter because Feret's diameter represents the distance between the two parallel planes orienting the object perpendicular to a particular direction. However, this variant was not included in previously described identification criteria because Feret's diameter is difficult to measure through microscopy. Using ImageJ software, we can measure Feret's diameter and consider this variant as a criterion to enhance the accuracy of measurement.

The roundness and centroid of the granules were also obtained (Table 2 and Figure 4D); similar to Feret's diameter, these variants can be used as important criteria in future studies. Considering that starch granules, which may also appear as oval granules, are not as round as wheat granules, we cannot easily determine the centroid of the starch granules under a microscopy. Thus, the centroid of granules should be determined to identify other plant species. Similarly, roundness is difficult to determine. Starch granules are usually depicted as round or oval because of the lack of some specific parameters. We found that the roundness of wheat, millet, and yam are distinguishable (Table 2 and Figure 6). The area, perimeter, and other parameters can also be simultaneously determined using ImageJ software. This software can be applied to obtain the above parameters automatically and efficiently, as well as to reduce subjective errors when these parameters are observed by different people (Collins, 2007; Tavarone et al., 2019).

The third aspect is that identification of starch granules requires extensive previous experience, necessitating an automated identification method to ensure that the starch granule fossil retrieved from an archaeological site is classified correctly according to the type of starch granules observed. Hence, we tested three starch granule fossils obtained from the investigated archaeological sites. We then used SPSS 20 software to process the data of geometric characteristics of each starch granule, as well as discriminant analysis to construct a discriminate formula that can correctly classify the ancient samples according to the type of starch granule. The discriminant scatter plot in Figure 6 shows that this method is viable. The ancient starch granules in Figures $5 A \sim C$ were successfully classified as wheat-type, millet-type, and yam-type. This new method was more efficient than the method described in our previous study.

Nevertheless, the entire process cannot be completely replaced with ImageJ. Hence, we cannot simply rely on the parameters obtained by this software to verify the species from which starch granules are derived. However, by using computer-assisted technology, we can rapidly obtain results and consider additional parameters, which can therefore allow accurate identification. 


\section{Conclusion}

In this study, starch granules were observed from samples of wheat seeds prior to maturity. Millet and yam samples were also processed. The mean size of wheat starch granules gradually increased with wheat seed growth. The wheat starch granules can be divided into large and small groups. This bimodal feature was considered as an identification criterion in traditional starch granule identification practices. Through ImageJ and SPSS software, data sets of geometric characteristics of wheat, millet, and yam starch granules were automated, reducing subjectivity in identification. To improve the efficiency in processing a large number of images obtained using a digital camera and a light microscope, as well as to obtain parameters objectively and automatically, we proposed the use of ImageJ and SPSS rather than traditional methods for morphotypological analysis. The processing results of ImageJ and SPSS are detailed and comparable to those directly obtained through light microscopy. Finally, the experiment on three ancient starch granules from archaeological sites successfully showed that discriminant analysis correctly classified them into existing groups, facilitating automated identification. Therefore, the combination of ImageJ and SPSS software is a promising technique for the morphotypological analysis of starch granules, which can facilitate automated identification of starch granule fossils in the future.

There are still some recommendations for future studies. (1) For the small round starch granules often extracted from archeological sites, it is likely that they are a smaller group of starch granules of wheat plants. In the future, detailed geometric morphological analysis can be performed on this part of starch granules, and a discriminant equation can be constructed for automatic identification, which can improve the accuracy of plant starch granule identification at archeological sites. (2) This article only tentatively analyzes the relevant starch granules of common crops in China. In the future, different regions can analyze the crops in their region and expand the scope of ancient recipe research. (3) The geometric morphological indicators of starch granules need to be strengthened. In the next step, more mathematical processing methods, such as Fourier transform and wavelet analysis, can be introduced to increase the use of existing data and improve the accuracy of discriminant analysis.

Acknowledgements. This study was supported by National Natural Science Foundation of China (41761045) and Open fund of Shandong Provincial Key Laboratory of Water and Soil Conservation and Environmental Protection (STKF201909). Thanks to the anonymous reviewers for their constructive comments, which greatly improved the quality of this article.

Conflict of Interests. The authors declare no conflict of interests.

\section{REFERENCES}

[1] Balter, M. (2007): Seeking agriculture's ancient roots. - Science 316(5833): 1830-1835.

[2] Barton, H., Torrence, R. (2015): Cooking up recipes for ancient starch: assessing current methodologies and looking to the future. - Journal of Archaeological Science 56(1): 194201.

[3] BeMiller, J. N., Whistler, R. L. (2009): Starch: chemistry and technology. - Academic Press, Burlington.

[4] Calo, C. M., Rizzutto, M. A., Watling, J., Furquim, L., Shock, M. P., Andrello, A. C., Appoloni, C. R., Freitas, F. O., Kistler, L., Zimpel, C. A., Hermenegildo, T., Neves, E. 
G., Pugliese, F. A. (2019): Study of plant remains from a fluvial shellmound (Monte Castelo, RO, Brazil) using the X-ray MicroCT imaging technique. - Journal of Archaeological Science: Reports 26: 101902.

[5] Ciofalo, A. J., Sinelli, P., Hofman, C. (2019): Late Precolonial Culinary Practices: Starch Analysis on Griddles from the Northern Caribbean. - Journal of Archaeological Method and Theory 26(4): 1632-1664.

[6] Collins, T. J. (2007): ImageJ for microscopy. - Biotechniques 43(1): 25-30.

[7] Coster, A. C., Field, J. H. (2015): What starch grain is that? A geometric morphometric approach to determining plant species origin. - Journal of Archaeological Science 58(1): 9-25.

[8] Cuthrell, R. Q., Murch, L. V. (2016): Archaeological laboratory extraction procedures and starch degradation: Effects of sonication, deflocculation, and hydrochloric acid on starch granule morphology. - Journal of Archaeological Science: Reports 9(1): 695-704.

[9] Diamond, J. (2002): Evolution, consequences and future of plant and animal domestication. - Nature 418(6898): 700-707.

[10] Drazic, S., Sladoje, N., Lindblad, J. (2016): Estimation of Feret's diameter from pixel coverage representation of a shape. - Pattern Recognition Letters 80(1): 37-45.

[11] Farley, G., Schneider, L., Clark, G., Haberle, S. G. (2018): A Late Holocene palaeoenvironmental reconstruction of Ulong Island, Palau, from starch grain, charcoal, and geochemistry analyses. - Journal of Archaeological Science: Reports 22: 248-256.

[12] Gremillion, K. J., Barton, L., Piperno, D. R. (2014): Particularism and the retreat from theory in the archaeology of agricultural origins. - Proceedings of the national academy of sciences of the United States of America 111(17): 6171-6177.

[13] Henry, A. G., Hudson, H. F., Piperno, D. R. (2009): Changes in starch grain morphologies from cooking. - Journal of Archaeological Science 36(3): 915-922.

[14] Herzog, N. M., Louderback, L. A., Pavlik, B. M. (2018): Effects of cultivation on tuber and starch granule morphometrics of Solanum jamesii and implications for interpretation of the archaeological record. - Journal of Archaeological Science 98(1): 1-6.

[15] Isobe, A., Akaji, M., Kurokawa, S. (2013): Proposal of New Polishing Mechanism Based on Feret's Diameter of Contact Area between Polishing Pad and Wafer. - Japanese Journal of Applied Physics 52(12): 6503.

[16] Jones, M., Hunt, H., Lightfoot, E., Lister, D., Liu, X., Motuzaite-Matuzeviciute, G. (2011): Food globalization in prehistory. - World Archaeology 43(4): 665-675.

[17] Kendal, E., Karaman, M., Tekdal, S., Dogan, S. (2019): Analysis of Promising Barley (Hordeum vulgare L.) Lines Performance by Ammi and Gge Biplot in Multiple Traits and Environment. - Applied Ecology and Environmental Research 17(2): 5219-5233.

[18] Lentfer, C., Therin, M., Torrence, R. (2002): Starch Grains and Environmental Reconstruction: a Modern Test Case from West New Britain, Papua New Guinea. Journal of Archaeological Science 29(7): 687-698.

[19] Li, W., Pagán-Jiménez, J. R., Tsoraki, C., Yao, L., Van Gijn, A. (2020): Influence of grinding on the preservation of starch grains from rice. - Archaeometry 62(1): 157-171.

[20] Lu, H. Y., Zhang, J. P., Liu, K.-B., Wu, N. Q., Li, Y. M., Zhou, K. S., Ye, M. L., Zhang, T. Y., Zhang, H. J., Yang, X. Y., Shen, L. C., Xu, D. K., Li, Q. (2009): Earliest domestication of common millet (Panicum miliaceum) in East Asia extended to 10,000 years ago. - Proceedings of the national academy of sciences of the United States of America 106(18): 7367-7372.

[21] Mercader, J. (2009): Mozambican grass seed consumption during the Middle Stone Age. - Science 326(5960): 1680-1683.

[22] Mickleburgh, H. L., Laffoon, J. E., Pagán-Jiménez, J. R., Mol, A. A. A., Walters, S., Beier, Z. J. M., Hofman, C. L. (2019): Precolonial/early colonial human burials from the site of White Marl, Jamaica: New findings from recent rescue excavations. - International Journal of Osteoarchaeology 29(1): 155-161. 
[23] Moore, P. D. (1998): Plant domestication: Getting to the roots of tubers. - Nature 395(6700): 330-331.

[24] Owen, T., Field, J., Luu, S., Kokatha Aboriginal People, Stephenson, B., Coster, A. C. F. (2019): Ancient starch analysis of grinding stones from Kokatha Country, South Australia. - Journal of Archaeological Science: Reports 23(1): 178-188.

[25] Peng, H., Xu, C., Yuan, Y., Zha, L., Chen, H., Guan, L., Kang, L.-P., Yang, J., Wang, Y., Cao, L., Cheng, J., Huang, L. (2019): The earliest excipient products of Traditional Chinese Medicine: Identification and analysis of samples from wooden lacquer box unearthed from Haihunhou tomb in the Western Han Dynasty. - Chinese Science Bulletin 64(9): 935-947.

[26] Perry, L., Dickau, R., Zarrillo, S., Holst, I., Pearsall, D. M., Piperno, D. R., Berman, M. J., Cooke, R. G., Rademaker, K., Ranere, A. J., Raymond, J. S., Sandweiss, D. H., Scaramelli, F., Tarble, K., Zeidler, J. A. (2007): Starch fossils and the domestication and dispersal of chili peppers (Capsicum spp. L.) in the Americas. - Science 315(5814): 986988.

[27] Piperno, D. R., Weiss, E., Holst, I., Nadel, D. (2004): Processing of wild cereal grains in the Upper Palaeolithic revealed by starch grain analysis. - Nature 430: 670-673.

[28] Piperno, D. R., Ranere, A. J., Holst, I., Iriarte, J., Dickau, R. (2009): Starch grain and phytolith evidence for early ninth millennium BP maize from the Central Balsas River Valley, Mexico. - Proceedings of the national academy of sciences of the United States of America 106(13): 5019-5024.

[29] Schneider, C. A., Rasband, W. S., Eliceiri, K. W. (2012): NIH Image to ImageJ: 25 years of image analysis. - Nature methods 9(7): 671-675.

[30] Tavarone, A., de Los Milagros Colobig, M., Fabra, M. (2019): Late Holocene plant use in lowland central Argentina: Microfossil evidence from dental calculus. - Journal of Archaeological Science: Reports 26: 101895.

[31] Torrence, R., Barton, H. (2006): Ancient starch research. - Left Coast Press, Walnut Creek.

[32] Ugent, D., Pozorski, S., Pozorski, T. (1981): Prehistoric remains of the sweet potato from the Casma valley of Peru. - Phytologia 49(5): 401-415.

[33] Ugent, D., Dillehay, T., Ramirez, C. (1987): Potato remains from a Late Pleistocene settlement in southcentral Chile. - Economic Botany 41(1): 17-27.

[34] Vojteková, J., Vojtek, M., Tirpáková, A., Vlkolinská, I. (2019): Spatial Analysis of Pottery Presence at the Former Pobedim Hillfort (an Archeological Site in Slovakia). Sustainability 11(23): 6873.

[35] Wan, Z., Yang, X., Ge, Q., Jiang, M. (2011a): Morphological characteristics of starch grains of root and tuber plants in South China. - Quaternary Sciences 31(4): 736-745.

[36] Wan, Z., Yang, X., Ma, Z. (2011b): Morphological Change of Starch Grain Based on Simulated Experiment and its Significance of Agricultural Archaeology. - Agricultural Science and Technology 12(11): 1621-1624.

[37] Wan, Z., Yang, X., Ge, Q., Fan, C., Zhou, G., Jiang, M. (2012a): Starch grain analysis reveals Late Neolithic plant utilization in the middle reaches of the Ganjiang River. Science China Earth Sciences 55(12): 2084-2090.

[38] Wan, Z., Ma, Z., Yang, X., Zhang, C., Zhou, G., Fan, C., Ge, Q. (2012b): Starch residues from shell tools from sites of Xianrendong and Diaotonghuan and its implications for paleoclimate. - Quaternary sciences 32(2): 256-263.

[39] Weber, S., Fuller, D. Q. (2008): Millets and their role in early agriculture. - Pragdhara 18(1): 69-90.

[40] Wu, Y., Wang, C. (2011): EDF phytolith analysis from Heying site, southeast China, Shang-Zhou dynasties. - Microscopy research and technique 74(11): 1062-1068.

[41] Wu, Y., Yang, Y., Xiao, T., Gu, Z., Hill, D. V., Wang, C. (2014): Characterization of silica distribution in rice husk using Synchrotron Radiation $\mu \mathrm{CT}$ and its implications for archaeological interpretation. - Microscopy research and technique 77(10): 785-789. 
[42] Xu, L., Ma, X., Zhang, B., Zhang, Q., Zhao, P. (2019): Multi-analytical Studies of the Lime Mortars from the Yanxi Hall in the Yangxin Palace of the Palace Museum (Beijing). - Archaeometry 61(2): 309-326.

[43] Yang, X., Zhang, J., Perry, L., Ma, Z., Wan, Z., Li, M., Diao, X., Lu, H. (2012): From the modern to the archaeological: starch grains from millets and their wild relatives in China. - Journal of Archaeological Science 39(2): 247-254.

[44] Yang, X., Perry, L. (2013): Identification of ancient starch grains from the tribe Triticeae in the North China Plain. - Journal of Archaeological Science 40(8): 3170-3177.

[45] Yang, X. (2017): Ancient Starch Research in China: Progress and Problems. - Quaternary Sciences 37(1): 196-210.

[46] Zhu, Z., Yu, C., Luo, W., Miao, Y., Lu, Z., Liu, L., Yang, J. (2020): Accurate identification of the pastry contained in a ceramic pot excavated from Jurou Li's grave from the Jin dynasty (1115-1234 CE) in Xi'an, Shaanxi, China. - Archaeometry 62(1): $130-140$.

[47] Zupancich, A., Mutri, G., Caricola, I., Carra, M. L., Radini, A., Cristiani, E. (2019): The application of 3D modeling and spatial analysis in the study of groundstones used in wild plants processing. - Archaeological and Anthropological Sciences 11(9): 4801-4827. 